Portland State University

PDXScholar

5-7-1997

\title{
The Impact of Theories of Dialogic Epistemology on Composition Theory and Pedagogy
}

Kandy Sue Robertson

Portland State University

Follow this and additional works at: https://pdxscholar.library.pdx.edu/open_access_etds

Part of the Educational Methods Commons

Let us know how access to this document benefits you.

\section{Recommended Citation}

Robertson, Kandy Sue, "The Impact of Theories of Dialogic Epistemology on Composition Theory and Pedagogy" (1997). Dissertations and Theses. Paper 5824.

https://doi.org/10.15760/etd.7695

This Thesis is brought to you for free and open access. It has been accepted for inclusion in Dissertations and Theses by an authorized administrator of PDXScholar. Please contact us if we can make this document more accessible: pdxscholar@pdx.edu. 


\section{THESIS APPROVAL}

The abstract and thesis of Kandy Sue Robertson for the Master of Arts in English were presented May 7, 1997, and accepted by the thesis committee and the department.

COMMITTEE APPROVALS:

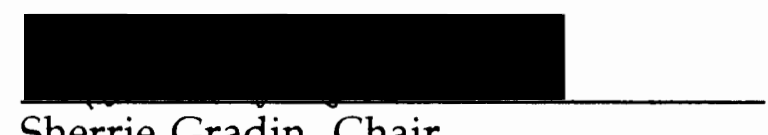

Sherrie Gradin, Chair

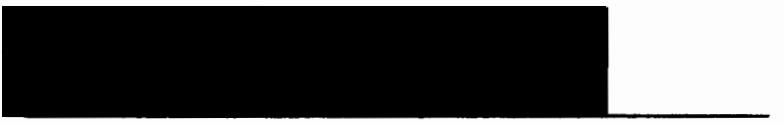

Duncan Carter
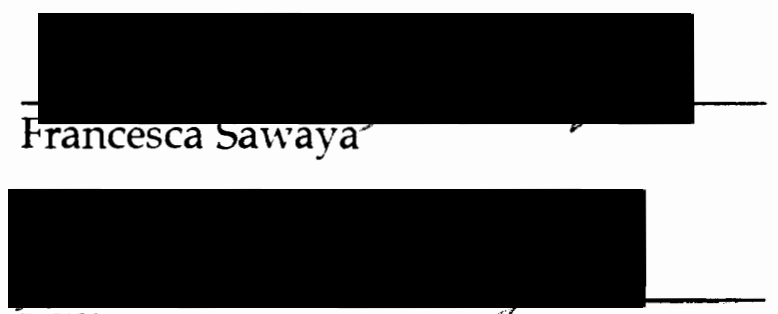

William Lang

Representative of the Office of

Graduate Studies

DEPARTMENT APPROVAL:

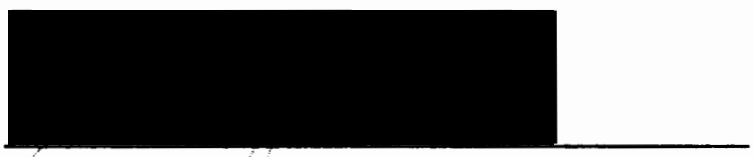

Shelley Reede

Chair, Department of English

ACCEPTED FOR PORTLAND STATE UNIVERSITY BY THE LIBRARY

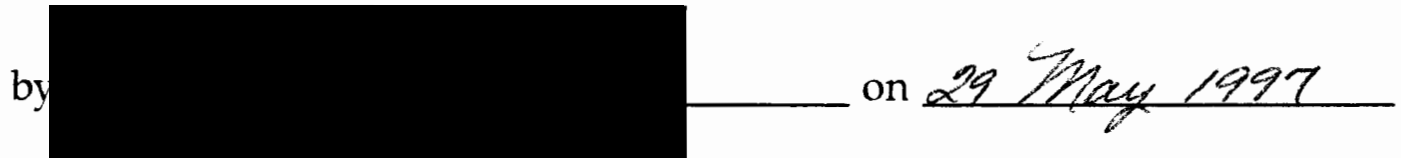




\section{ABSTRACT}

An abstract of the thesis of Kandy Sue Robertson for the Master of Arts in English, presented May 7, 1997.

Title: The Impact of Theories of Dialogic Epistemology on Composition Theory and Pedagogy

Dialogic epistemological theory dramatically changes traditional concepts of composition theory and pedagogy in several ways. First, it changes our understanding of the ways in which human beings acquire knowledge. By suggesting that the cognitive environment is dialogic, a product of consensus, rather than isolated within the individual, we come to understand knowledge as a product of experience and interpretation rather than a fixed quantity waiting to be discovered.

Second, dialogic epistemology had changed our concept of the way in which classrooms are configured as well as the ways in which they function. The notion of learning through dialogue facilitates collaboration as a legitimate method for teaching writing, a radical contrast to the image of the solitary writer, isolated by her craft.

Third, by empowering students, dialogic epistemology changes the relationship between students and the teacher. It undermines 
traditional hierarchies, substituting a more egalitarian approach to this relationship. Teachers and students become co-learners, sharing ideas and strategies.

Finally, dialogic epistemology changes the ways in which composition teachers approach the assessment of student texts. Because process-based pedagogy focuses on multiple drafts through feedback and revision, the emphasis on stylistic error becomes secondary to issues of critical engagement with the topic, organization of ideas, and the clear communication of those ideas.

This thesis is an in-depth discussion about the relationship between the dialogic nature of knowledge acquisition and the dialogic nature of the process approach to writing and how this relationship affects composition theory and pedagogy. 
THE IMPACT OF THEORIES OF DIALOGIC EPISTEMOLOGY ON COMPOSITION THEORY AND PEDAGOGY

$$
\text { by }
$$

KANDY SUE ROBERTSON

A thesis submitted in partial fulfillment of the requirements for the degree of

\author{
MASTER OF ARTS \\ in \\ ENGLISH
}

Portland State University

1997 
TABLE OF CONTENTS

PAGE

PREFACE $\ldots \ldots \ldots \ldots \ldots \ldots \ldots$ ii

\section{CHAPTER}

1 BEGINNING AT THE BEGINNING

The Dialogic Episteme . . . . . . . . . . . . . 1

2 THE EXPRESSIVE TEXT

Dialogue With The Inner Voice . . . . . . . . . . 11

3 COLLABORATION

Dialogue With Others . . . . . . . . . . . . 23

4 EVALUATION

The Teacher/Student Dialogue . . . . . . . . . . . 34

$5 \quad$ CONCLUSION $\ldots \ldots \ldots \ldots \ldots \ldots \ldots \ldots \ldots \ldots$

WORKS CTTED . . . . . . . . . . . . . . . . . . 55 


\section{PREFACE}

As I began to consider composition theories and their influence on pedagogy, I sensed a common element derived from theories of the dialogic nature of human epistemology. Thus, rather than embarking on a pragmatic examination of how theory might be integrated into the methodology or praxis of pedagogy, I was drawn into a discussion of how the knowing process affects the writing process. It became increasingly clear to me that the dialogic nature of knowledge acquisition and the dialogic nature of writing are not only intrinsic to communication, but to the ways in which human beings define and redefine reality as well.

This fundamental relationship between defining reality, writing, and learning suggests the motivation behind the dialogic emphasis in composition theory since the 1960s. Thus, this thesis is a discussion, a dialogue if you will, on the way in which awareness of dialogic epistemological theory effects the development of expressive pedagogy, collaborative learning strategies, and assessment methods. It is, in itself, a dialogue because it not only forefronts the dialogic episteme, but it asks the 
reader to respond both within the realm of the inner voice and within the classroom.

It is important to understand the way in which I differentiate between the terms "discourse" and "dialogue." In my view, dialogue is an interaction between two or more voices. Richard Rorty, Lev Vygotsky and others argue that knowing begins with dialogue, the interaction of external stimuli with the inner human voice. They explore the way in which this interaction expands as the individual grows and experiences the world. As individuals enter and obtain membership in diverse communities of discourse, they encounter language that is based on an established set of conventions to which they must adapt in order to participate effectively within the group. The language used within the community is the discourse of that group. As individuals then proceed to become more expert in this new language, they eventually achieve membership or a unity of understanding with that community. Rorty discusses this movement as the transition from normal to abnormal and back to normal discourse. Thus, dialogue is the methodology of human thought.

This thesis is a dialogue with you, the reader, through a discourse that encompasses the academic conventions of research and the community of composition theory. Once I have established the basis for my theoretical stance, the progression of this thesis is outward, beginning 
with the dialogue with the inner voice, proceeding to the collaborative dialogue with others, and concluding with a discussion of the student/ teacher dialogue of assessment.

In Chapter 1, I will define The Dialogic Episteme through the notion that dialogic epistemology is the motivating force behind current trends in composition theory and pedagogy. Specifically the relationship between expressive and academic writing, the development of collaborative pedagogy, and the incorporation of dialogue in assessment strategies. It is my view that teaching, like learning, is a continuous process that begs constant "re-visioning." My goal is to present a discussion that will encourage readers to consider ways in which dialogic approaches to composition pedagogy might prove useful in the classroom.

In Chapter 2, I will begin my discussion of the dialogic episteme in expressivist composition theory. I will consider the Dialogue With the Inner Voice and the ways in which this dialogue encourages writers to write. This discussion will be couched in expressivist notions of writing as process and will particularly consider Donald Murray's ideas on the value of expressive writing as an alternative to current-traditional modeling and Peter Elbow's thoughts on defining academic discourse. I will also respond to concerns about the "anti-intellectual" nature of expressive writing with a discussion of the ways in which the dialogue with the inner voice 
anticipates pre-writing and expands outward to include membership in the academic discourse community. It is my goal in this chapter to offer definitions of expressivist writing and academic writing that connect the two rather than place them at opposition. In this way I hope to open a dialogue in which readers can respond to their own notions of expressivist writing and perhaps redefine the role it plays in their pedagogy.

Chapter 3 is a discussion of collaboration or a Dialogue With Others. Here I will examine collaborative theory, including the concerns of educators like Donald Stewart on the implications of collaborative pedagogy. I will discuss the ways in which this pedagogy redefines the classroom setting and the teacher/student relationship. My goal in this chapter is to respond to these concerns in such a manner that a "middle ground" becomes evident, facilitating the reader's consideration of collaborative methodology as a viable way in which to enhance the discourse community of the classroom.

Drawing from my discussion of the changing nature of the teacher/student relationship, in Chapter 4 I will examine what I consider to be the most difficult element of that relationship--assessment. In this discussion, I will draw from the research and methods of current composition scholars and from my own personal experiences both with these methods and my own. In order to illustrate my personal approach to 
evaluation, I will use a section from several drafts of a student text and explain the rationale behind my response to those texts. Finally, I will discuss the dialogic nature of portfolio assessment and the advantages of this method to process-based pedagogies. 


\section{CHAPTER 1}

\section{BEGINNING AT THE BEGINNING:}

The Dialogic Episteme

When examining the nature of the relationship between contemporary composition theory and pedagogy, it is important to note that pedagogy always assumes an epistemology. While frequently separated in composition texts, the relationship between theory and praxis is intrinsically interdependent. Paulo Freire defines praxis as "action" and "serious reflection" as a way of responding to societal changes (47). In the same way, action and reflection are valuable strategies for responding to societal changes within the composition classroom. In this way, epistemology drives theory, theory drives praxis, and praxis drives pedagogy. Theories suggesting that the cognitive environment or episteme is in some way dialogic are particularly significant to compositionists because they are useful in explicating writers' relationships with themselves, the language, and the audience. The notion of cognition, then, becomes a starting point in defining these relationships and their 
effect on pedagogy.

In his essay "The Voice of Poetry in the Conversation of Mankind," Michael Oakeshott states,

As civilized human beings, we are the inheritors, neither of an inquiry about ourselves and the world, nor of an accumulating body of information, but of a conversation, begun in the primeval forests and extended and made more articulate in the course of centuries. It is a conversation which goes on both in public and within each of ourselves. . . And it is this conversation which, in the end, gives place and character to every human activity and utterance. (199)

Thus, epistemology, according to Oakeshott, exists in the realm of conversation, or dialogue. It is this relationship between knowing and conversing, between thinking and speech, that facilitates the popular notion of collaborative pedagogy.

Kenneth Bruffee, a proponent of collaborative pedagogy in composition theory, views Oakeshott's remarks as a response to the "Kuhnian assumption that knowledge is a consensus: it is something people construct interdependently by talking together" (113). Kuhn concludes that knowledge is "intrinsically the common property of a group 
or else nothing at all" (qtd. in Bruffee 113). In other words, Kuhn sets up the concept of knowledge as consensus, thus presupposing group discourse, and Oakeshott uses this concept to suggest that conversation, as intrinsic to consensus and thus knowledge, is what separates human beings from other animal life.

Lev Vygotsky expands this concept a bit further by suggesting that, as human beings developing an epistemological base, we master conversational skills first, only to internalize them as we begin to think reflectively. Hence we have a process of development that takes us from first cognition to membership in what Stanley Fish calls complex "interpretive" (discourse) "communities" (14).

In an article titled "The Amazing Minds of Infants," Lisa Grunwald discusses current research on the cognitive ability of infants ranging in age from birth to one year. Grunwald cites the work of University of Denver psychologist Marshall Haith, who has discovered that by placing infants in a black box with TV cameras displaying different sequences of colorful images above them, the infants will, after only four or five observations, begin to anticipate the sequence. Haith says that the "babies are not just looking. They're analyzing, creating little hypotheses" (Grunwald 49). In Kuhnian terms, the infants are developing consensual relationships with the colorful images by acknowledging the sequences of occurrence. These 
relationships indicate the infants' ability to think and hypothesize without language.

Another psychologist, Carolyn Rovee-Collier of Rutgers University, notes the amazing specificity of infant memory. Rovee-Collier places infants as young as two and a half months in cribs with elaborate mobiles, which she connects with ribbon to the child's leg. The infants kick in order to make the mobile move. Several weeks later, she places the infants in the same environment, without the connective ribbon, and the infants kick in a remembered attempt to make the mobile move. Interestingly, if one or more of the elements of the mobile are removed, the infants do not kick. Rovee-Collier states,

When we change things, it wipes out the memory. But as soon as we bring back what had become familiar and expected, the memory comes right back. What we've learned from this is that even at two and a half months, an infant's memory is very developed, very specific and incredibly detailed. (Grunwald 49)

This might also seem to indicate that the infants are aware of the specific appearance of the correspondent in the original discourse community; they shy away from attempting membership in a discourse environment in which the conventions are unfamiliar. This same sense of reluctance is 
often experienced by writers who, because they are unfamiliar with the discourse of a specific community, hesitate to take risks in their writing. Instead, they resort to general statements that do not engage their topic with any sense of critical evaluation.

Bruffee, in his book on the merits of collaborative pedagogy titled Collaborative Learning: Higher Education, Interdependence, and the Authority of Knowledge, cites the work of Jerome Burner with six-monthold children.

This experiment demonstrates what Bruner calls 'enactive' knowledge, which he describes in the language of inner-outer, subject-object foundational cognitive thought. Infants can learn how to affect their surroundings (by sucking [a pacifier] to focus or blur a picture), he says because their minds are equipped even in infancy with a 'hypothesis generator' that gives them the ability to form either higher-order action routines or more generalized 'cognitive maps' of their world. (162)

Thus, Bruffee continues,

To construe Bruner's scene as a conversation, therefore, is to enlarge its implications. It confirms Vygotsky's observation of six-month-old infants establishing contact with reality 
through a mediated process involving the agency of other people. (162)

In other words, this process does not wait for, nor is it contingent upon speech or language acquisition. Thus cognitive dialogue begins in a need/response cycle that is ultimately facilitated by language.

This need/response concept of cognition is further explicated by anthropologist Clifford Geertz who suggests that

Human thought is consummately social: social in its origins, social in its functions, social in its form, social in its applications. (360)

By combining this concept with the notion of the discourse community, we can examine ways in which the rites of passage from one discourse community to the next occur, and begin to understand the effect of this movement on composition theory and ultimately, pedagogy.

Contemporary philosopher Richard Rorty uses Kuhn's scientific model to divide discourse into two realms; normal and abnormal discourse. Rorty defines normal discourse as that which is conducted within an agreed-upon set of conventions about what counts as a relevant contribution, what counts as answering a question, what counts as having a good argument for that answer or a good criticism of it. (320) 
In other words, normal discourse is what takes place in any conversational community in which the participant is a member. Membership implies that the conversant is familiar with and in consensus with the conventions of that community. It is a cognitive environment in which we feel comfortable. Bruffee suggests that the "goal" of normal discourse is to "maintain and confirm established knowledge" (123).

In contrast, Rorty defines abnormal discourse as what happens when someone joins in the discourse who is ignorant of these [normal discourse] conventions or who sets them aside. ... The product of abnormal discourse can be anything from nonsense to intellectual revolution, and there is no discipline which describes it, any more than there is a discipline devoted to the study of the unpredictable, or of 'creativity.' (320)

Rorty positions the interaction between normal and abnormal discourse, or the movement from one community into another, under the rubric of epistemology which he then further contrasts with hermeneutics.

But hermeneutics is the study of an abnormal discourse from the point of view of some normal discourse-the attempt to make some sense of what is going on at a stage where we are still too unsure about it to describe it, and thereby to begin an 
epistemological account of it. (320-1)

Hermeneutics, then, is the aberrations that occur within the transitional phase between the personal discourse/experience of the individual and the new discourse community being entered. Rorty contends that we are hermeneutical when we "do not understand what is happening but are honest enough to admit it" (321).

Learners cannot acquire new knowledge without participating in this process. In other words, if there is a way to get there from here, this is the only road in. This is not to say that the road is the same for everyone. On the contrary, the nature of abnormal discourse is subjective. Each person will make the same transition, but from individualized perspectives that are the sum of that person's membership experiences in many discourse communities. This both problematizes and facilitates composition research. In order to define writing as a "process," cognitive researchers must attempt to assign the subjective (the individual) to specific categories. This method is reductive because the categories would necessarily be subjective in themselves, requiring a new classification for each individual. Thus, the research is intrinsically limited by its own paradoxical nature. On the other hand, the social nature of this movement facilitates writing as a way of defining and redefining the reality of the individual within the group. 
Rorty suggests that our understanding of knowledge occurs through a consensus with a given community or a "social justification of belief" (170). Thus we reject the Aristotelian quest for the recognition of "truth" because of this social belief system and the authority it lends to normal discourse. It is this validation of authority that motivates us as human beings to enter into the process of defining and redefining reality. We desire new knowledge that has value because it is justified by a system of social belief that we agree to adhere to.

If we look at this dialogic process as a whole, the movement from knowledge as conversation to collaborative learning as a characteristic intrinsic to human cognitive behavior becomes inevitable. In his examination of "Culture, Music, and Collaborative Learning," anthropologist/ethnomusicologist Charles Keil looks at the notion of collaborative and thus discursive thought and the evolution of society. Keil notes the work of Stanley Diamond, who "defines and abstracts various aspects of prismatic pieces of one holistic, primitive gathering and hunting society" (327). Keil agrees with Diamond and Colin Turnbull (The Forest People 1961) who suggest that people in primitive societies don't abstract concepts from lived experience and reify them the way post-Platonic literate people do. They don't insist that each person become a 
madman or a specialist. Who you are and what you know are not separable. (328)

This speaks to Rorty's concept of social justification. The suggestion of a unity between ontology and epistemology seems to make the quest for membership in increasingly complex discourse communities an inevitable factor of human cognitive development. Left to their own devices, human beings will inevitably learn through community discourse and thus the nature of that knowledge is defined by that process. On a broader level, "'collaborative learning' is just another name for our prime species being in the process of creating genuine culture" (Keil 330).

If we then consider ontological epistemology as human cognitive development that operates as a sort of Hegelian dialectic, moving from normal discourse to abnormal discourse which can then be reacculturated, or synthesized into normal discourse, the relationship between this epistemological theory and composition theory becomes clear. We learn through dialogue within a given community. Composition theory is the methodology through which we transpose that dialogue into text. 


\section{CHAPTER 2}

\section{THE EXPRESSIVE TEXT:}

Dialogue With the Inner Voice

In his essay "Liberal Education, Writing, and the Dialogic Self," Don Bialostosky states:

Dialogics differs from other social theories of discourse in its vision of ideologically situated persons involved in struggles over the meanings of things and the ownership of words. It de-emphasizes rhetorical commonplaces, calling attention instead to the appropriated, if not always proper places of persons who have identified themselves with certain words, ideas, ways of talking and social positions. (15)

Dialogics involves the ways in which language about the external world allows the individual to position themselves in a way that reflects their internal values. It is the discourse that we carry on with our inner voice. This discourse not only determines the way in which we process and define what goes on around us, "reality," but it facilitates a safety zone 
separating us from unfamiliar, and often intimidating, discourse communities. It is this discourse that emerges in the personal narrative and thus forms an important element of expressivist pedagogy. An examination of theories concerning human interaction with the inner voice will provide insight into the rationale behind teaching academic writing through the personal experience essay--one common element of expressivist pedagogy. Such an examination will also connect the dialogic nature of epistemology with theories of writing process.

Expressive writing can be defined as a written textualization of individual experience. It is a testimony to the conversation between the writer's individual discourse and the perceived reality in which that discourse functions. Mikhail Bakhtin argues that while this conversation is internal, and thus entirely subjective to the individual conversant, it can only occur in borrowed language. While this language is outside of any "authoritative" discourse community (academic, social, religious, etc.) it maintains its own sense of authority as a construct of individual experience, perception, and definition. Thus, according to Bakhtin, the individual appropriates the utterances of everyday experience, adapting the language of others to form a subjective definition of reality. Bakhtin explains:

Another's discourse performs here no longer as information, 
directions, rules, models and so forth-rbut strives rather to determine the very bases of our ideological interrelations with the world, the very basis of our behavior; it performs here as authoritative discourse, and an internally persuasive discourse. (342)

Thus expressive writers function within the realm of personal experience, creating their own authority and textualizing ideas from that perspective. Some educators resist acknowledging the authority of the personal perspective and this reluctance, combined with the borrowed nature of the inner word, invalidate expressive writing, relegating it to a position outside of the academy. They contend that because there is no solid model or theory (in the academic sense) in expressive writing, it is counterproductive to the teaching of composition, and for some, antiacademic. Such a stance denies the legitimacy of the authorial voice and ignores the function of competency within the individual inner dialogue. It is this competency that allows the writer to initiate movement into other discourse communities which facilitates learning and knowledge acquisition.

Within the realm of composition, expressivist theory contends that writing is a process that evolves, differently for each individual, and subsequently produces a product. The emphasis is heavily focused on the 
process partially in response to the current traditional notion of an established mode (EDNA) that can be modeled. Keeping this in mind, Bakhtin's concept of the "internally persuasive word" (345) and its relationship to inner speech seems to clearly locate the conversation with the inner voice at the starting point (pre-prewriting) of the process, also placing it in opposition with its rigid model counterpart. Bakhtin explains: Internally persuasive discourse--as opposed to one that is externally authoritative--is, as it is affirmed through assimilation, tightly interwoven with "one's own word." In the everyday rounds of our consciousness, the internally persuasive word is half-ours and half-someone else's. Its creativity and productiveness consist precisely in the fact that such a word awakens new and independent words, that it organizes masses of our words from within, and does not remain in an isolated and static condition. It is not so much interpreted by us as it is further, that is freely, developed, applied to new material, now conditions; it enters into interanimating relationships with new contexts. (345-6)

This definition lends itself to the creative nature of expressive writing. Therein lies the rub. How can a creative form of writing teach, or even accommodate academic discourse? 
The answer to this question lies, in part, in the relationship between the writer and the audience. In his essay "I , You, and It," James Moffett defines the first of four "stages of discourse:"

Consider, if you will, those primary moments of experience that are necessarily the raw stuff of all discourse. . . My perceptual apparatus is recording these moments of raw experience, not in words but in some code of its own that leads to words. (24)

What Moffett is describing is the way in which human beings respond to external events internally. Moffett suggests that the four stages of discourse, "inner verbalization, outer vocalization, correspondence, and formal writing" (25), create a continuum by "increasing the distance, in all senses between speaker and audience" (25). Thus it is at the point of inner verbalization that the speaker and audience are closest because they are one and the same. Moffett further explains that as the distance between the writer and the audience increases, the discourse becomes increasingly more analytical moving from chronological (what happened) to analogical (how or why did it happen). If we think of narrative or creative writing as chronological, the move toward analytical writing would seem to be a matter of distancing the writer from the audience. Moffett writes:

The audience is, first, the speaker himself, then another 
person standing before him, then someone in another time and place but having some personal relation to the speaker, then, lastly, an unknown mass extended over time and space. The activity necessarily changes form thinking to speaking to writing to publishing. (25)

Thus the relationship between the writer and the audience seems to include expressive and academic writing within the same continuum rather than isolating one from the other.

Donald Murray responds to the challenge that creative writing is inappropriate for the composition curriculum in his essay "Our Students Will Write--If We Let Them." Murray argues that the desire to write is a "human hunger to record and examine experience" (149) and that the problem with writing classes lies in the reluctance to allow students the freedom to record creatively:

It is time that we, as a profession, not only support the reading of literature but the making of literature; that we encourage our students to write what they want to write and realize that what they want to write is more intellectually demanding, more linguistically challenging, more rhetorically difficult than the writing we usually require in the English class. (148) In this bold statement Murray suggests that teachers incorporate the 
personal narrative, the textualized dialogue with the inner voice, into a curriculum whose aim is traditionally to teach academic (analytical) writing. He is thus acknowledging the value of the student writer's internally persuasive discourse as well as the potential of this discourse as a pedagogical doorway.

Murray continues to define specifically what such a curriculum might include:

1. Teach process not product. The traditional English class appropriately deals with a product--finished writing. The writing class deals with unfinished writing, writing that is in the process of discovering meaning. Students must have the time to pass through the same stages of prewriting, writing, rewriting and editing which writers have to pass through to achieve the products we examine in other parts of the English curriculum.

2. Write yourself. The writing teacher prepares for the writing class by using his or her own language to examine and share experience. The teacher understands the writing process because the teacher experiences it.

3. Listen to your students. The center of the writing course is the conference in which the student evaluates the draft and 
the teacher responds to that evaluation. Students who are experiencing the process understand it better than we can. They know what is going well, what isn't going well, and they can, with our coaching, see how to improve their writing--to move closer to their meaning. (150)

Like collaborative pedagogy, Murray's curriculum acknowledges the change in the teacher student relationship. While the teacher's role remains one of leadership, it becomes significantly more egalitarian, recognizing the student's involvement in his or her own writing process. This recognition facilitates the dialogue of conferencing and thus clearly situates the notion of dialogue as an integral part of a new teacher/student relationship.

Murray also suggests a progression that begins with the student's development of a personal relationship with language, a type of inner speech, in which he or she becomes competent before approaching more traditionally academic writing assignments. This concept of a progression clearly aligns Murray with Moffett and Bakhtin in that it recognizes the student's need to establish competency at the inner level before making the move outward into different discourse communities. In other words, this competency enables creativity in analytical writing and this ability has the potential to liberate the ways in which students grapple with difficult 
issues through writing.

It is important to note that this discussion is not suggesting a tradeoff between expressive and academic writing. Rather, it suggests a state of cooperation between the two. In his essay "Reflections on Academic Discourse: How It Relates to Freshmen and Colleagues," Peter Elbow defines academic discourse:

It's essentially a rhetorical definition: giving reasons and evidence, yes, but doing so as a person speaking with acknowledged interest to others--whose interest and position one acknowledges and tries to understand. (142)

In comparison to Moffett's expressive model, the distance established between the writer and the audience is clear. However, this definition also seems to allow for Bakhtin's internally persuasive discourse--creativity. There is no model, rather objectives to be achieved in the relationship with the reader. Elbow continues:

Though this intellectual stance is characteristic of academic discourse at its best, it is also characteristic of much nonacademic discourse--such as that produced by writers like Montaigne, Woolf, Orwell, Paul Goodman, even William Gass or Joan Didion. If I get my students to achieve this admirable stance in their writing, they still might not be 
producing what most professors would call academic discourse or look for in assigned essays. (142)

Thus Moffett's continuum. Here Elbow seems to recognize that once composition pedagogy moves beyond strict adherence to the modes and modeling, expressive writing achieves a valid place in the classroom.

In light of Elbow's definition, the question of academic standards and curriculum objectives becomes moot. Expressive writing not only facilitates the development of an individual writing process, it facilitates the move into the academic discourse community as well. Also, it is important to note that expressive writing is what students like to do. Elbow contends that

the best test of a writing course is whether it makes students more likely to use writing in their lives: perhaps to write notes and letters to friends or loved ones; perhaps to write in a diary or to make sense of what's happening in their lives; perhaps to write in a learning journal to figure out a difficult subject they are studying; perhaps to write stories or poems for themselves or for informal circulation or even for serious publication; perhaps to write in the public realm such as letters to the newspaper or broadsides on dormitory walls. I don't rule out the writing of academic discourse by choice, but 
if we teach only academic discourse we will surely fail at this most important goal of helping students use writing by choice in their lives. (136)

What Elbow is advocating is a balance that will benefit students both before and after graduation. Once students understand writing as a process that begins with their own inner discourse and moves outward into the world they must grapple with and define, they will come to appreciate the ways in which writing, as an expression of this inner discourse as well as their participation and membership in other discourse communities, can become an important element of their lives. It is the teacher's role to nurture that awareness through participation in the student's dialogue and by facilitating the discourse community of the classroom.

It is interesting to note, as Irene Ward points out in her book Literacy, Ideology, and Dialogue: Towards a Dialogic Pedagogy, that there is an irony in the relationship between expressivist theory and the social implications of defining reality. Many composition scholars contend that expressive writing is "self-discovery" (Ward 47) and thus separate from social interaction. It seems evident, however, that Bakhtin's focus on experiential discourse and Moffett's notion of a continuum suggest otherwise. In fact, it is difficult to imagine writing without social influence. 
Sherrie Gradin addresses this paradox in her Romancing Rhetorics: Social Expressivist Perspectives on the Teaching of Writing:

[I]n refusing the idea of an objective self and embracing that of a subjective one, the self is always changed, created and constantly recreated by the community that self is in. (114) What Gradin is suggesting is the inseparable influence of society on the self. Expressive writing is unavoidably tied to issues of time, place, culture, race, class, and gender because the individual is inextricably submersed in their influence. Thus Gradin offers "social-expressivism" as a way of defining this relationship.

Within the context of pedagogy, we can not bifurcate the curriculum in order to isolate the individual from the social, nor should we want to. The discourse community of the classroom inevitably contains many diverse voices. it is only through a collaboration of these voices, speaking together, that knowledge is acquired and it is our goal, as teachers, to facilitate that dialogue.

Thus expressive writing becomes much more than the recording of experiences. It becomes a communal voice that embraces increasingly complex definitions of the world as the voice expands and grows. It becomes the analytical process of academic writing. 


\section{CHAPTER 3}

\section{COLLABORATION:}

\section{Dialogue With Others}

The dialogic nature of collaborative pedagogy makes it a perfect vehicle for the expressive communal voice. By facilitating new and increasingly focused discourse communities within the classroom, teachers facilitate the expansion of that voice and thus the students' ability to redefine the world from new, more critically informed perspectives. For some educators, however, collaborative classroom strategies are problematic. Donald Stewart, for instance, in response to a collaborative pedagogy suggested by Kenneth Bruffee, is concerned about Bruffee's "rather flexible definition of the word collaboration, specifically its lack of a clear distinction between influence and collaboration" (103). Stewart asks, when we say that we are influenced by someone, or that such and such a composer is influenced by his predecessors, even in the sense in which T. S. Eliot used the word in 'Tradition and the Individual Talent,' are we asked to extend 
collaboration to mean the effects of absorbed learning? How does one account for the originality of genius? (103)

First, Stewart is concerned with the notion of authority. Who is the author of a collaborative text? Is there a voice not heard (genius, feminist, minority)? Also, Stewart questions the power of consensus to suppress the voice of the "other" and thus create an influence that will stifle rather than emancipate writers. Stewart cites Eric Fromm:

He [Fromm] says that the sense of self, the sense by which one experiences himself as the true center of his world, is what it means to be original. 'To feel a sense of self, a sense of identity, is a necessity for every human being. We would become insane unless we had such a sense of self .... As man proceeds in the process of evolution and emerges as an individual, his sense of identity becomes separated from that of the group.' (111)

Here Stewart seems to reject the notion of the inner dialogue and thus severs the dialogue between the self and the world, at least within the development of identity. This severance seems like a return to the Platonic notion of knowledge as separate from expression. However, if we consider the notion of knowledge as dialogic, this seems to suggest that there is some way of envisioning knowledge as, in a Derridian sense, fluid; 
something that can be extended, or that intrinsically extends, beyond some arbitrary system of limits. If there is a relationship between epistemology and discourse, which Rorty certainly contends and the research cited in Chapter 1 suggests, then it seems reasonable that the transition process that moves us from one discourse community to another exemplifies the same sense of Derridian fluidity. The process is fluid because knowledge itself expands in the same fluid motion.

Approaching Stewart's concerns from another direction, Michel Foucault, in his Archaeology of Knowledge, discusses the "formation of objects," or the ways in which human beings define and redefine reality. Using psychopathology as a vehicle, Foucault describes the functioning of imagination:

First we must map the first surfaces of their [objects of discourse] emergence : show where these individual differences, which, according to the degrees of rationalization, conceptual codes, and types of theory, will be accorded the status of disease, alienation, anomaly, dementia, neurosis or psychosis, degeneration, etc., and may emerge, and then be designated and analyzed. These surfaces of emergence are not the same for different societies, at different periods, and in different forms of discourse. (1130) 
Thus Foucault posits that the originality or "genius" that concerns Stewart emerges from an attempt to define or redefine an object using what Rorty calls "hermeneutics." Once the definition of the object is established, the learner has successfully negotiated entry into another normal discourse. In other words, without the dialogically-based experience that Rorty labels "ontological epistemology," knowledge, and especially genius, is impossible. Ideas do not simply spring forth in some sort of Platonic realization of truth, they are a product of discourse--collaboration between a human being and an "other." Therefore, the Rortian notion of abnormal discourse and hermeneutics seems to allow for a process through which Stewart's silenced voices can be an integral part of consensus. Keeping this in mind, the composition teacher can strive to facilitate dialogue that includes rather than overrides these voices.

Also, if we consider the relationship between ontology and epistemology as in some way unified (Rorty, Geertz, Keil, Turnbull, Bruffee), then for identity to be isolated, taken out of conversation with any discourse community, would be to undermine knowledge and thus threaten the dynamic fluidity of acquisition and expansion. This threat, in turn, would seem to undermine the self. However, the research of Grunwald, Haith, and Rovee-Collier seems to suggest that this isolation would have to occur very early in the individual's life. Thus, while not all 
discourse is collaborative, the individual cannot avoid membership in some kind of discourse. And it is, in fact, this membership that allows the individual to acquire knowledge and define reality.

The fundamental premise that drives collaborative theory is the integration of the dialogic nature of human epistemology into the classroom; particularly, for the purposes of this discussion, the composition classroom. Bruffee cites the "consensus group" as a model of this pedagogy :

In consensus groups people work collaboratively on a limited but open-ended task, negotiating among themselves what they think and know in order to arrive at some kind of consensus or agreement, including, sometimes, agreement to disagree. (28)

In this model, the students use discourse and the evolution of a discourse community to create Foucault's "surface of emergence"--to redefine the object of discourse in order to meet the parameters of the assigned task.

The most significant aspects of this model are the ways in which it transforms the traditional classroom. Not only are the physical parameters of the classroom affected, but the student/teacher relationship becomes more egalitarian as teaching and learning responsibilities merge. This merging is in many ways liberating for both teachers and students as ideas 
flow more freely and the discourse expands more rapidly. The model, however, becomes problematic for some educators because it engenders analogies that seem to devalue the teacher's role. Bruffee's "social director" example is typical:

[T] he teacher acts a bit like a social director at a vacation resort or summer camp, counting students off, wading in to help them rearrange chairs, separating groups to minimize noise from other conversations, and encouraging group members to draw close enough together to hear one another over the din and to make the group more likely to cohere. (29) This description is decontextualized and demeaning; it relegates the teacher to the role of caretaker and presupposes the Platonic idea of knowledge as intrinsically known, awaiting discovery. Thus, because of the dialogic nature of epistemology, it is essential to consider collaborative pedagogy holistically.

Foucault's notion of the contextual nature of experience illustrates the relationship between the teacher and the class as a whole. The teacher establishes the boundaries of the class by providing the task and facilitating the direction the class will move in order to achieve those goals. As a function of this movement, the class becomes a discourse community made up of the students and the teacher. The teacher then divides the 
community into smaller communities or collaborative groups which in turn each establish their own discourse community; separate, but remaining a part of the whole. Within these smaller groups, each individual student draws on the experience of the dialogue to create surfaces of emergence for new definitions of reality. These redefinitions converge as the class reunites to continue the discourse as a community that once again includes the teacher, whose ideas are a part of, but not prescriptive to the discussion. In this way, collaborative pedagogy is both communal (dialogic) and individualistic.

In his essay "The Structure of Classroom Discourse," Hugh Mehan discusses "the internal structure of classroom lessons." Mehan describes the process of information exchange as one that occurs in "elicitation sequences." Mehan explains that "these sequences have three interconnected parts: an initiation act, a reply act, and an evaluation act" (121). Thus, as teachers and students engage in the process of acculturation that will move them from one discourse community [student] to another [teacher/student/class], meaning becomes facilitated by this series of actions.

In a traditional classroom, the teacher is always responsible for the initiation act, the students reply, and the teacher, in turn, evaluates and responds to the reply in a positive or negative manner. The collaborative 
classroom allows for a modification of this hierarchy. In what Ira Shor calls the "liberatory" classroom (after Freire's model), "learning itself challenges structures of control" (96), like the teacher-centered model. Shor states,

As a transcendent mode of teaching, dialogics integrate a theory of discourse, subject matter and political power... . The act of study needs to be thought of as an act of cultural democratization; democratic relations in class legitimize the critique of oppression; students experience freedom while examining the forces which impede freedom.... This dialectic action disrupts the routine submission to authority in and out of school. Ordinary roles become problematic--the teacher no longer issues commands and the students no longer can fall back on authority-dependence. The extraordinary disruption of familiar order empowers students. (96)

Thus, by relinquishing their authoritarian role, teachers empower their students and facilitate the genesis of expanding discourse communities through which their students can evolve and learn.

Empowering students in this manner allows them the role of initiator and shifts the teacher into the role of facilitator. While the 
difference between these roles is often only negligible, the effect of this freedom is substantial. In his essay “The General Nature of Peer Group Influence," Theodore Newcomb finds that [peer] groups have power over their members because the same processes of interaction that result in the members' feeling favorably toward each other also result simultaneously in their adopting norms that enable them to aim at success rather than failure. (4-5)

In other words, by allowing students to participate in formulating the criteria for their own acculturation processes, teachers facilitate their entry into the target discourse community. Students working in groups and participating in open classroom discussions seem to acculturate normal discourse more successfully than students restricted by the traditional teacher/student hierarchy.

Finally, it is important to note that collaborative pedagogy functions at every stage of the writing process. As the invention or idea-formulating process described earlier becomes written text, collaboration in the form of feedback becomes essential to the writer's success. Feedback can come from a variety of sources. Mina Shaughnessy, in her seminal essay "Some New Approaches Toward Teaching," discusses the "connections and distinctions between speech, writing, and reading" (149). She states that writing 
produces a distinctive circuitry in which the writer continually feeds back to himself (as writer and reader) and acts upon that feedback at any point and for as long a time as he wishes before his statement is finally put into circulation. (150)

In a collaborative classroom, writers are exposed to additional feedback on several levels. First, as they engage in the class discussion, their ideas are subjected to the process of social justification and they have the opportunity to adjust to the conventions of the discourse community of the class. Second, in small group discussions, they have the opportunity for further fine-tuning and for establishing themselves as members of the group. Then, through the peer review process, students receive direct feedback, usually directly on the text. These external strategies in turn expand and strengthen students' internal feedback processes, enabling them to have a more informed perspective on their own writing. Also, by participating in the peer review of their classmates' work, they become more efficient editors and more effective readers. Finally, through conferencing, students are able to dialogue with the teacher on any specific concerns they have about their writing and receive immediate response. Often the teacher can offer specific strategies to assist students in developing their writing process. In turn, students discuss their process 
with the teacher, providing insight into the ways in which the teacher can be more effective. Thus, while collaborative pedagogy changes the ways in which the traditional classroom functions and the student/teacher relationship, the nature of these changes is positive. 


\section{CHAPTER 4}

\section{EVALUATION: \\ The Teacher/Student Dialogue}

Perhaps the most difficult dialogue that ensues as a part of the writing process occurs between students and teachers, particularly writing teachers, and especially writing teachers who embrace process writing as a fundamental element of their pedagogy. As Peter Elbow suggests, we strive to encourage writing as an element of students' lives both inside and outside of the classroom. We want our students to enjoy writing and to be able to use it effectively to enhance their lives. Thus, we approach evaluation of our students' writing with a great deal of angst.

As a first-year Graduate Teaching Assistant it was not unusual for me to spend hours laboring over one essay. Where should I begin? Should I deal with grammar issues in a first draft? What about tone? Organization? Logic? Does the paper answer the "so what" question? How do I approach a sensitive topic in a personal narrative essay? These 
are a few of the thousands of questions that consumed me as I read. I was constantly at war with the urge to fall back on my current traditional background and grab for the red pen. At the same time, I was convinced that writing evaluation should open a dialogue with the student, present options, and not simply point out mistakes.

Slowly, because teaching is a process that evolves just like writing, I began to gain some perspective on how to approach my students' writing. The first decision I made was never to look at grammar in a first draft. Even if the grammar was so bad that it hampered my ability to make meaning out of the writing. In fact, I decided to leave grammar issues to the final draft. This is not to say that I did not hand out my share of punctuation worksheets, but I clearly announced, as I assigned each essay, that I did not look at grammar in a first draft. The effects of this strategy were well worth any stumbling I did making my way through sentence fragments and subject verb disagreements. First there was an almost audible sigh of relief, but that was not the best part. I began to notice that some students, those who believed me, began taking risks in their draftsrisks that they might not have taken had they been concentrating on stylistic correctness. The papers got, well, interesting.

Donald Murray notes that one of the biggest problems with writing teachers is that they do not have enough faith in their students' writing. I 
was determined to at least attempt Murray's level of faith. My experience in Writing Centers at two different universities taught me the importance of confidence and that confidence is contagious. I found that when I approached first drafts as a sounding board for ideas, the first step in an exploratory process, my students would respond more readily to my comments and suggestions than when my approach was more prescriptive. Peter Elbow writes that

[T]he essential skill in all revising is the ability to look at your own writing and see potentialities: see what is almost there or sort of there or even to see what is not there at all but ought to be. (Power 145)

I wanted my evaluation process to begin by looking for, and exploring potentialities. In this way the evaluation process and teaching the writing process intermingled and each facilitated the other. I realized that by approaching my students' papers in this way, my evaluation process was much more than assigning a grade. It involved instilling confidence, making discoveries, and learning with my students that sometimes it is okay-even helpful- to quit and start again.

The following is an example of how I approach the first draft of a student's essay. This student, I will call him Bob, is responding to an essay by Paulo Freire called "The 'Banking' Concept of Education." The 
assignment was to analyze Freire's concepts of pedagogy through the lens of personal experience. This type of assignment facilitates dialogue in several ways. First, it opens a dialogue between the student and the text in which the student can be an active participant. Also, in class, this assignment presented the opportunity to discuss perspective and how interpretation is a product of experience. Finally, the students spent time in small groups discussing ways of approaching the assignment and brainstorming ideas for their opening paragraphs.

Bob's opening is in many ways typical. He begins with very broad statements as he attempts to situate himself in both Freire's text and his own.

In the modern world, education is a vital commodity. Without an education, it is difficult for an individual to develop and achieve the status that they desire. The manner in which a child is educated is important because it sets the parameters for the future of that child.

In this modern world, many new forms of education are created. Many tax-dollars could be saved if Paulo Freire's article "The Banking Concept of Education" was read before school districts and departments attempted new forms of education. 
In these first two paragraphs, the repetition of the phrase "In the/this modern world" seems to suggest that Bob is trying out different approaches, attempting to prioritize his main points. As I evaluate these paragraphs, I want to help Bob develop a sense of focus. By asking him to define what he means by "status" in the first paragraph, I hope to encourage him to think about his perception of education and how it relates to goals. I also hope to start him thinking about the implications of the ways in which education establishes boundaries for the student's future. These issues play into Freire's ideas about oppressive education on a more sophisticated level than just comparing banking and problem posing pedagogy. I want to encourage Bob to make those connections. My written dialogue with Bob, in the margins of his essay, read as follows:

What do you mean by "status"--economic, social, academic? Is there a way in which these are all related? In what ways does education create boundaries for student goals? Does the student participate in setting these boundaries? How does this idea [boundaries] relate to Freire's notion of oppressive pedagogy? It is my sense that these two paragraphs are closely related. Can you think of a way to combine them?

In his second draft, Bob responded to several, but not all of these questions. 
In the modern world, education is a vital commodity. Without an education, it is difficult for an individual to develop and achieve the "two car and a house," archetypal American dream. The manner in which a child is educated is important because it sets the parameters for the future of that child. As their part in achieving the archetypal dream school districts around the nation are in a quest for better methods of education. Many tax-dollars could be saved if Paulo Freire's article "The 'Banking' Concept of Education" was read before school districts put new methods of education into action. Bob has defined "status" as the "American dream" consisting of "two car[s] and a house." By associating "school districts" with the ability to achieve the "archetypal dream," which indirectly implicates them in setting "parameters" for student success, it seems as if Bob is beginning to approach the question of culpability. While he still needs to make the connection with Freire's notion of oppression more clear, he seems to be taking steps in that direction. Also, Bob has incorporated the two paragraphs into one that is, while still vague, more focused than his first draft.

The next step in my evaluation/teaching process with Bob was a conference. Conferencing is an integral part of my pedagogy. In this one- 
on-one dialogue, I gather insights into my students' critical thinking and writing processes. I am able to offer instant feedback and I invite the student to be frank in their response to that feedback. I try to establish the student's ownership of the essay, and assure them that my suggestions are just that--suggestions--that they can accept or reject. This is not to say that I do not argue my point from time to time, but the final decision belongs to the student.

While some students cannot seem to get away from automatically taking teacher suggestions as "edicts," Bob had no difficulty accepting this relationship. I quickly discovered that Bob was very proud of his revision. We talked at length about his focus and I suggested that perhaps he might want to establish the direction of his paper more clearly in the opening paragraph. I told Bob that I liked the way in which he had combined the two paragraphs and suggested that while his interpretation of status was more clear, I was still not sure about his reasons for recommending Freire's theory. Bob stated that he liked the revised opening because it was a clear statement of his perspective and that the reader would understand his point of view.

At this point I decided that it was time for me to back off. If I was going to stand true to my word, Bob would have the final say about the revision of his paper. This stance is not always an easy one. Peter Elbow 
writes that

when we write for "real audiences" like teachers and employers, the stakes are very high and we get too clenched. What's more we are liable, without realizing it, to feel the reader as enemy. After all, they are the enemy: they've hurt us deeply time and again in the past, the dirty bastards. When, on the other hand, we feel the reader as genuine friend and ally, suddenly words flow more easily and humanly. (Power 144-5)

I was determined to facilitate the kind of writing environment that allows the words to flow. I decided that if I was going to believe in writing as a process, I had to have faith in the process and allow it to work. This is the point at which I was thankful for the "no grades" policy. (I will discuss this policy later.) I could allow Bob to continue with his revision process without having to be the "dirty bastard" who gave him a " $\mathrm{C}$ " on his essay. Rather than shutting him down, I encouraged him to move forward.

Bob's response to this pedagogy was interesting--he compromised. He kept the first paragraph exactly as it was in his second draft; however, the rest of his paper reflected the emphasis on defining terms and clearly stating objectives that we had discussed in our conference. For example, in his first draft, paragraph three read: 
In his article Paulo Freire attacks a notion known as the "banking" concept. Though the concept and approach to teaching can be detrimental in some cases, the "banking " concept of education still has a place in education. Freire's article also deals with the notions of alienation and praxis. Freire feels that the alienation form of teaching is detrimental to the learning and development of student, and feels the idea of praxis to be the most prudent style of teaching. The idea of alienation, would be a situation where a student would sit in a classroom setting, and without any interaction between the student and the teacher, the student would be forced to take in information as the teacher lectures. In contrast to alienation, praxis involves a one on one interaction between the student and the teacher. The ultimate form of education doesn't seam [sic] to apply completely to either alienation or praxis, but a combination of both methods of teaching.

As in the first paragraphs cited earlier, Bob's perspective is vague because many of his terms remain inadequately defined. He concludes the paragraph with an interesting hypothesis that the reader struggles with because Bob does not explain enough about alienation or praxis to create a clear picture of a combination of the two. Notice how his approach 
changes in his final draft:

In his article, "The 'Banking' Concept of Education," Paulo Freire attacks a notion known as the "banking" concept of education as,

Education thus becomes an act of depositing, in which the students are the depositories and the teacher is the depositor. Instead of communicating, the teacher issues communiques and makes deposits which the student patiently receive, memorize, and repeat. (213)

Though the concept of "banking" can be detrimental in some cases, some elements of the "banking" concept of education do have a place in education. To examine "banking", Freire deals with the notions of alienation and praxis. The idea of alienation, would be a situation where a student would sit in a classroom setting, and without any interaction between the student and the teacher, the student would be forced to take in information as the teacher lectures. A contrast to alienation, praxis involves a one on one interaction between the student and the teacher where discussion take [sic] place allowing both 
the teacher and the student to learn. Freire dislikes the idea of alienation and feels that praxis is the most prudent style of teaching,

Students, as they are increasingly posed with problems relating themselves in the world and with the world, will feel increasingly challenged and obliged to respond to that challenge. (219)

In my view, [sic] ultimate form of education is a combination of both methods of education, alienation and praxis.

While he makes similar points in both drafts, Bob is clearly engaging Freire at a more critical level in the revised draft. By directing his definition of alienation and praxis pedagogy through the quotations from Freire, Bob clarifies his point and readers can begin to understand how he might combine these opposing pedagogies to create the "ultimate form" in spite of the negative nature of alienation.

In evaluating Bob's work, I took into consideration things like his more aggressive engagement of Freire, his positive attitude toward revision, and his utilization of feedback. It seems to me that Bob made progress in his critical evaluation of Freire; in his ability to look at, and revise, his writing effectively; in his understanding of the value of feedback; and in his concept of the value of his opinion in the class. All of 
these things indicate that Bob is becoming a more effective writer. It is my belief that if he continues to develop his writing process, Bob's confidence will increase and writing will become an experience he incorporates into his life because he enjoys doing it.

It is important to understand that this is not to say that I am giving Bob an "E for effort." It is my view that evaluation as a part of my pedagogy is also a part of the process of writing because ultimately grades are the unavoidable bottom line no matter how stridently I resist this premise as a teacher. The development of Bob's final grade in my class depends on his progress toward developing his own writing process as well as his ability to produce an "A" paper; two elements I see as inextricably tied together.

There is a certain irony in the way in which students approach grades. Students typically dread grades. They fear them. Many students spend hours trying to "divine" exactly what it is that their professor wants in a paper. This becomes a sort of challenge for some. Students who have the ability to "figure out" their professors are envied by their peers. In fact, the only thing I have found that intimidates students more than a grade is the notion of no grades. The section of my first syllabus titled "Grades" read:

Because I feel strongly that feedback and improvement are more important than an arbitrary letter of the alphabet, the 
emphasis in this class will be on the process and development of your writing.

My students were visibly nervous. They asked questions like, "Does this mean you're not going to grade our papers?" and "How will we know if we're passing?" Being a student myself, I understood their concerns and added "I am available to discuss your progress in this class at any time" to the syllabus both to allay their fears and to emphasize my own "open door" policy.

Eventually, due to popular demand, I also included a percentage break-down of the final grade that consisted of $70 \%$ of the grade derived from the student's portfolio scores, $20 \%$ derived from class participation and attendance, and 10\% derived from participation in an email journal. While I realize that, from the students' perspective, essentially what I did was to exchange an arbitrary letter of the alphabet for an equally arbitrary percentage, this break-down made the students feel more at ease without changing my process-based evaluation system. I say that the percentage break-down is arbitrary because in order to score well on the portfolio students must participate in class discussions, invention/brainstorming groups, peer reviews, group discussions, in-class freewriting and spontaneous essays, and teacher conferences. In other words, very few students are able to produce a really top-rate portfolio without participating 
in and developing their own writing process. Ironically, those few who can are so engaged with writing as a part of their lives that they have already developed a process and they are usually very anxious to share their experience with the class.

Another advantage to not assigning grades was that it underscored the idea that no paper is ever beyond one more revision. While students realized that for the purposes of the class, there was a "final" draft, they also came to understand revision as a vital part of the writing process and one of the things that I value as a teacher (for those who were trying to figure me out). Again, evaluation and writing pedagogy seemed to merge. Rather than basing my evaluation on "error free" writing, I focused on the student's efforts toward a better draft. This focus also seemed to free students to take risks in their writing, risks that could always be changed in a subsequent draft.

This pedagogical stance begs the question of academic standards, and whether or not it is possible to uphold a competent standard while creating a writing environment without Elbow's "enemies." In his essay "Bringing Practice in Line with Theory: Using Portfolio Grading in the Composition Classroom," Jeffrey Sommers contends that portfolio assessment offers a method by which teachers can create a writing environment that is not grade driven. While I am an enthusiastic supporter of portfolio 
assessment, I think it is important to solidify my stance on the issue of grade-driven pedagogy before I discuss the merits of the portfolio process. It is my view that the nature of the academy is grade-driven. We cannot avoid this. Students enter the university to pursue specific goals and the way in which they achieve these goals is by learning. The way in which the academy establishes and validates standards, and thus quantifies learning is through grades. Thus, it seems unlikely that any writing environment, regardless of how it is constructed, will effectively eliminate the stress caused by grades. Students will always, at some level, consider grades an intrinsic element of their educational experience. This is not to say that we, as teachers, cannot facilitate a writing environment that minimizes grade stress. It is in the achieving of this goal that portfolio assessment becomes a valuable tool.

Portfolios can be modeled in various ways. For example, a portfolio can be an overview that includes selected drafts, peer reviews, freewrites, and journal entries generated for a specific class. While this model presents often insurmountable paper loads, it does provide a precise record of the students' drafting process and the evolution of their critical thinking skills. It also provides the teacher with a vast body of material to evaluate which, while beneficial from one perspective, has its drawbacks in the amount of reading time required. 
When employed as a "gatekeeper," part or all of the portfolio can be directed to respond to a specific question or issue. In this way the portfolio demonstrates the student's ability to dialogue with the reader in and around the suggested topic. This strategy is much more effective than standardized testing because it challenges students to set their own boundaries and explore depths of inquiry beyond a set of given options. It also provides evaluators with useful insight into the student's strengths and weaknesses, thus facilitating more effective placement decisions.

In another form that limits the contents of the portfolio to a specified body of work, portfolios can provide a rich, textured view of the student's work, incorporating the selection process, a type of dialogue between the student and her text, in the criteria for scoring. My experience with this model in both upper-division composition courses and on challenge exams has convinced me that selection is an important element in scoring because it demonstrates the students' ability to evaluate their own writing from several perspectives. Students often reject a paper they perceive as "well written" in favor of one that is more significant on a personal level. This selection process often leads to further drafting which enhances the writer's process as well as the portfolio.

In my evaluation process, portfolio assessment functions on several levels. As $70 \%$ of the final grade, portfolio assessment evaluates students' 
ability to apply the writing skills that they have developed throughout the term. Sommers suggests:

Portfolio assessment in the composition classroom offers not a methodology but a framework for response. . . the portfolio approach presents an opportunity for instructors to bring their practice in responding to student writing in line with their theories of composing and pedagogy. (153)

In other words, because revision is such a fundamental element of process pedagogy, the portfolio, with its focus on multiple drafts, allows teachers to integrate process-based theory into their evaluation process.

While in some portfolio programs an instructor is solely responsible for reading and scoring the portfolios generated by his or her students, other programs recruit groups of writing faculty and graduate teaching assistants to act as scoring panels. The scoring panel option creates the need for a dialogue between the writing instructors prior to the actual assessment. This dialogue evolves at the developmental level to establish the criteria for the assessment, and at the process level as teachers discuss their assignment strategies and personal pedagogy in preparation for the reading. Thus, in the same way that collaboration benefits the writing process, programmatic portfolio assessment can benefit teacher development as well as overall program coherence. 
Because portfolios engage writing as a process of revision, evaluation, and choice, they can become a capstone to process-based pedagogies. I also see portfolio assessment as the only current option for minimalizing grade-stress in the composition classroom. The notion that a paper is never beyond one more revision significantly reduces the pressure to "perform or fail" and allows students to concentrate on developing competence within their own writing process. This competence instills confidence and makes the writing experience less intimidating. Also, the notion of an "open-dialogue" between student and student, student and text, and student and teacher creates a low-stress writing classroom environment that encourages students' confidence in their own writing.

Personally, I like the way in which portfolio assessment fits my pedagogy. It facilitates a relationship with my students that allows me, as a teacher, to offer options rather than point to error. 


\section{CHAPTER 5}

\section{CONCLUSION}

The goal of education should always be to motivate students to learn. Concepts of what they should learn and the environment in which they should learn have shaped pedagogy in all disciplines. These concepts have also shaped traditional notions of the teacher/student hierarchy and the way in which that hierarchy mirrors authority relationships in society. Dialogic epistemological theory dramatically changes these traditional concepts in several ways. First, it changes our understanding of the ways in which human beings acquire knowledge. By suggesting that the cognitive environment is dialogic, a product of consensus, rather than isolated within the individual, we come to understand knowledge as a product of experience and interpretation rather than a fixed quantity waiting to be discovered.

This epistemological shift is particularly significant for teachers of composition because it is the impetus for the movement away from model-based pedagogy toward a pedagogy whose focus is ultimately process 
rather than product. It has thus opened the door for a theory of composition which seems to bring with it a sense of validation for composition as a discipline within the academy.

Second, dialogic epistemology has changed our concept of the way in which classrooms are configured as well as the ways in which they function. The notion of learning through dialogue facilitates collaboration as a legitimate method for teaching writing, a radical contrast to the image of the solitary writer, isolated by her craft. Our goal for the contemporary composition classroom is a writing environment in which students can develop a sense of their own writing process and, with the help of their peers, refine and "re-vision" that process. We allow the rigid structure of the classroom to become messy; small clusters of desks huddled together replace straight, ordered rows. As we begin to value collaboration as a pedagogy, we also begin to value the student as a legitimate participant in that pedagogy.

Third, by empowering students, dialogic epistemology changes the relationship between students and the teacher. It undermines traditional hierarchies, substituting a more egalitarian approach to this relationship. Teachers and students become co-learners, sharing ideas and strategies. Free from traditional roles, teachers can encourage students, offering options rather than pointing to error, thus the dialogic structure values all 
participants in the dialogue as intrinsic to achieving the goals set forth by the group.

Finally, dialogic epistemology changes the ways in which composition teachers approach the assessment of student texts. Because process-based pedagogy focuses on multiple drafts through feedback and revision, the emphasis on stylistic error becomes secondary to issues of critical engagement with the topic, organization of ideas, and the clear communication of those ideas. Through portfolio assessment, students can participate in the selection of their work to be assessed. In this way, students learn to evaluate the entire corpus of their writing holistically and reflect on the strengths and weakness of each piece of writing individually. This process gives students an active role in the evaluation of their work.

While the goal of motivating students to learn has not changed, the impact of dialogic theories of epistemology has transformed the ways in which educators achieve that goal. What is perhaps most significant about these changes is that they encourage students to associate the writing process and the learning process. It is this association that will instill writing as a part of their lives in the academy and in society. 
Works Cited

Bakhtin, Mikhail M. The Dialogic Imagination. Ed. Michael Holquist. Austin: Texas UP, 1981.

Bialostosky, Don H. "Liberal Education, Writing, and the Dialogic Self." Contending with Words: Composition and Rhetoric in a Postmodern Age. Eds. Patricia Harkin and John Schilb. New York: MLA, 1991. 11-22.

Bruffee, Kenneth A. Collaborative Learning: Higher Education, Interdependence, and the Authority of Knowledge. Baltimore: Johns Hopkins UP, 1993.

Elbow, Peter. "Reflections on Academic Discourse: How It Relates to Freshmen and Colleagues." College English. 53:2 February (1991) 135-155.

- Writing With Power: Techniques for Mastering the Writing Process. New York: Oxford UP, 1981.

Fish, Stanley. Is There a Text in This Class?: The Authority of Interpretive Communities. Cambridge: Harvard UP, 1980. 
Foucault, Michel. The Archaeology of Knowledge and the Discourse on Language. Trans. A.M. Sheridan Smith. New York: Pantheon, 1972.

Freire, Paulo. Pedagogy of the Oppressed. New York: Continuum. 1996.

Geertz, Clifford. The Interpretation of Cultures: Selected Essays. New York: Basic Books, 1973.

Gradin, Sherrie. Romancing Rhetorics: Social Expressive Perspectives on the Teaching of Writing. Portsmouth: Boynton/Cook, 1995.

Grunwald, Lisa. "The Amazing Minds of Infants." Life . (1993) July, 4660.

Keil, Charles. "Culture, Music, and Collaborative Learning," The Politics of Culture and Creativity: A Critique of Civilization. Ed.

Christine Ward Gailey. Gainesville: Florida UP, 1992.

Mehan, Hugh. "The Structure of Classroom Discourse." The Handbook of Discourse Analysis: Discourse and Dialogue. Vol.3 Ed. Teun A.Van Dijk. London: Academic Press, 1985. 119-131.

Moffett, James. "I, You, and It." College Composition and Communication. 16, (1965) 243-48.

Murray, Donald M. Learning by Teaching: Selected Articles on Writing and Teaching. Portsmouth: Boynton/Cook, 1982. 
Newcomb, Theodore M. "The General Nature of Peer Group

Influence." College Peer Groups: Problems and Prospects for

Research. Eds. Theodore M. Newcomb and Everett K. Wilson.

Chicago: Aldine, 1966. 2-16.

Oakeshott, Michael. "The Voice of Poetry in the Conversation of

Mankind." Rationalism in Politics. New York: Basic Books, 1962.

Rorty, Richard. Philosophy and the Mirror of Nature. Princeton:

Princeton UP, 1979.

Shaughnessy, Mina. "Some New Approaches to Teaching." Composition in Four Keys: Inquiring Into the Field. Eds. Mark Wiley, Barbara Gleason, and Louise Wetherbee Phelps. Mountain View: Mayfield, 1996. $149-156$.

Shor, Ira. Critical Teaching and Everyday Life. Boston: South End Press, 1980.

Sommers, Jeffrey. "Bringing Practice in Line with Theory: Using Portfolio Grading in the Composition Classroom." Portfolios: Process and Product. Eds. Pat Belanoff and Marcia Dickson. Portsmouth: Boynton/Cook, 1991. 153-164.

Stewart, Donald C. "Collaborative Learning: Boon or Bane?" Rhetoric Review. 7 (1988): 58-83. 
Ward, Irene. Literacy, Ideology, and Dialogue: Towards a Dialogic

Pedagogy. New York: New York State UP, 1994. 